\title{
Conservadores y derechistas en Iberoamérica en los últimos dos siglos
}

\section{Conservatives and Rightists in Ibero-America in the Last Two Centuries}

DANIEL LVOVICH ${ }^{1}$ https://orcid.org/0000-0001-7469-3960

${ }^{1}$ Instituto del Desarrollo Humano

Universidad Nacional de General Sarmiento - CONICET Juan María Gutiérrez, 1150, Los Polvorines, Buenos Aires, Argentina daniel.lvovich@gmail.com

Obra reseñada:

KOLAR, Fabio y MÜCKE, Ulrich (eds.). El pensamiento conservador y derechista en América Latina, España y Portugal, Siglos XIX y XX. Madrid: Iberoamericana-Vervuert, 2019. 362p.

Los textos que componen El pensamiento conservador y derechista en América Latina, España y Portugal, Siglos XIX y XX, volumen compilado por Fabio Kolar y Ulrich Mücke son resultado de las ponencias presentadas originalmente en un simposio que se realizó en Hamburgo en 2016. Se trata de un libro ambicioso en sus alcances geográficos y temporales, ya que incluye textos sobre distintos, países latinoamericanos, España y Portugal, desde comienzos del siglo XIX hasta fines del siglo XX.

En la introducción del texto, a cargo de Kolar y Mücke, se destacan las dificultades que supuso para el estudio de esta tradición el uso poco preciso y en ocasiones arbitrario de conceptos como derecha y conservador. Los compiladores asimismo señalan la necesidad de articular, en

Recibido: 14 abr. 2019 | Aprobado: 22 jun. 2019

http://dx.doi.org/10.1590/0104-87752019000300010

Varia Historia, Belo Horizonte, vol. 35, n. 69, p. 955-958, set/dez 2019 
el plano temporal, los elementos heredados de las tradiciones políticas conservadoras con las novedades propias del siglo XX; y en el plano de las escalas la combinación entre las historias políticas e intelectuales nacionales con los elementos propios de una historia regional o global, para dar cuenta de la especificidad de cada caso en el marco de sus conexiones transnacionales (KOLAR; MÜCKE, 2019, p.7-36).

Los temas que los compiladores eligen presentar como ejes para el análisis de la tradición derechista y conservadora en sus continuidades y rupturas son los de la soberanía y la revolución, la Iglesia y la religión, las mujeres y el género, las masas y las élites, la circulación de lecturas y el problema del anticomunismo, el fascismo y las dictaduras.

No todos los textos que integran la compilación responden del mismo modo a las aspiraciones de renovación historiográfica expuestos en la introducción - como el empleo de las herramientas de la historia intelectual y la combinación de escalas de análisis - aunque todos ellos son sólidos y bien fundamentados. De hecho, es perceptible una distancia entre la tradición cultural en que se insertan y la biblioteca en que se respaldan los compiladores y las de los autores, de modo que su articulación no resulta siempre sencilla.

Varios trabajos abordan el temprano siglo XIX. Lucia Pereira das Neves estudia los lenguajes políticos de conservadores y lliberales en la época de la independencia del Imperio de Brasil, mostrando los modos en que más allá de la implantación de algunos principios liberales, la vida pública no se extendió más allá de la elite. Víctor Peralta Ruiz analiza el pensamiento político del realismo antiliberal en Perú en los años de las guerras de independencia, al que considera un movimiento reactivo y reacio al liberalismo español, estudiando para ello tres momentos relevantes de esa tradición conservadora.

En una mirada de largo plazo sobre el siglo XIX, Marta García Ugarte destaca la centralidad política y la heterogeneidad del catolicismo mexicano, proponiendo como clave interpretativa que la modernidad resulto connatural a la catolicidad. Por su parte, Benjamin de Losada estudia el pensamiento de Pedro Gual y Pujadas, franciscano español que expresó el pensamiento ultramontano en el Perú de la segunda mitad 
del siglo XIX. El análisis en el marco de una "cultura atlántica de la confrontación" permite al autor mostrar las peculiaridades del vínculo entre catolicismo y republicanismo en América del Sur. Tributario de la perspectiva de Quentin Skinner, el aporte de Erika Pani analiza las formulaciones conservadoras sobre el pueblo en el marco de la Guerra de Reforma mexicana, mostrando los modos en que el conflicto funcionó como un límite a la hora de desarrollar iniciativas que consideraran de un modo efectivo la soberanía popular.

Eduardo González Calleja expone en su trabajo la larga y heterogénea tradición conservadora española de defensa armada de un orden social al que se consideraba amenazado, desde la década de 1840 hasta la conformación del Somatén Nacional, entendido como un eslabón intermedio entre las formas tradicionales de movilización reactiva y las modalidades de radicalización de las derechas.

Ricardo Arias Trujillo discute las visiones tradicionales sobre el conservatismo colombiano entre 1880 y 1930 proponiendo una visión de esta tradición que - más allá de su relación intrínseca con el catolicismo - resultó sumamente heterogénea, de manera que su consideración como una fuerza reaccionaria ha impedido dar cuenta de la existencia en su seno de sectores que defendieron la democracia y el laicismo.

Entrando de lleno en la historia del siglo XX, dos trabajos examinan en particular la problemática de la historia de las mujeres. Para el caso portugués bajo el salazarismo, Irene Flusner Pimentel da cuenta de la situación de subordinación femenina en el Estado Novo, lo que no impidió la movilización política de las mujeres ni la tardía formación de una elite femenina en el seno del régimen. Por su parte, Margaret Power, a través del análisis del caso de la movilización de las mujeres anticomunistas contra Goulart en Brasil y contra Allende en Chile muestra - apelando al análisis transnacional y comparado - la coexistencia en su discursividad de tópicos en común, propios del anticomunismo global de la época de la guerra fría, conviviendo con otros enraizados nacionalmente, como la importancia diferencial de la apelación al catolicismo en cada caso.

Un enfoque igualmente trasnacional y comparado se encuentra en el trabajo de Ernesto Bohoslavsky, Magdalena Broquetas y Gabriela 
Gomes dedicado al estudio de organizaciones juveniles conservadoras en Argentina, Chile y Uruguay entre 1958 y 1973. Atentos al impacto común del discurso anticomunista trasnacional, y a las redes que lo sostenían, cuanto a los rasgos que particularizan cada experiencia nacional, el articulo sostiene que las diferencias ideológicas entre estos grupos y los propios de la derecha revolucionaria no ocluye la existencia de un repertorio de acciones violentas y de un enemigo definido de manera similar que los emparenta.

El aporte de João Fabio Bertonha se ubica en un estilo de reflexión conceptual. Partiendo de la constatación de que existieron múltiples conexiones entre las derechas latinoamericanas de entreguerras y los fascismos, el autor sostiene que existió un fascismo latinoamericano con rasgos diferenciales respecto a sus coetáneos europeos, y propone - sin llegar a una conclusión definitiva - discutir y evaluar la utilidad del concepto de fascismo ibérico. Por último, Riccardo Marchi estudia el tránsito de una elite universitaria identificada con el nacionalismo revolucionario en los años finales del Estado Novo portugués hacia el liberal-conservadurismo, en un proceso que es explicado por el anacronismo de su lenguaje original ante el fin del imperio colonial, y por la incorporación del lenguaje político predominante en Europa y Norteamérica en los años setenta y ochenta como parte de homogenización política e ideológica del período.

Más allá de la marcada heterogeneidad de las contribuciones que constituyen esta obra, Conservadores y derechistas es una valorable contribución a un campo en expansión, y un libro que instiga a los historiadores de América Latina y Europa a profundizar el diálogo, así como un instrumento que nos ayude a pensar en la génesis del fenómeno de las derechas y su radicalización en nuestros días y a pensar claves analíticas para su comprensión.

\section{REFERENCIAS BIBLIOGRÁFICAS}

Kolar, Fabio y Mücke, Ulrich (eds.). El pensamiento conservador y derechista en América Latina, España y Portugal, Siglos XIX y XX. Madrid: Iberoamericana-Vervuert, 2019. 